\title{
Interactive comment on "Vertical and horizontal distribution of sub-micron aerosol chemical composition and physical characteristics across Northern India, during the pre-monsoon and monsoon seasons" by James Brooks et al.
}

James Brooks et al.

james.brooks-2@manchester.ac.uk

Received and published: 18 March 2019

Thank you very much to the useful and constructive referee comments. The responses have been uploaded in the form of a supplement: https://www.atmos-chem-physdiscuss.net/acp-2018-1109/acp-2018-1109-AC1-supplement.pdf 
Interactive comment on Atmos. Chem. Phys. Discuss., https://doi.org/10.5194/acp-2018-1109, 2018.
ACPD

Interactive

comment 